This article was downloaded by: [University Library Utrecht]

On: 05 February 2015, At: 03:32

Publisher: Routledge

Informa Ltd Registered in England and Wales Registered Number: 1072954 Registered office: Mortimer House, 37-41 Mortimer Street, London W1T 3J H, UK

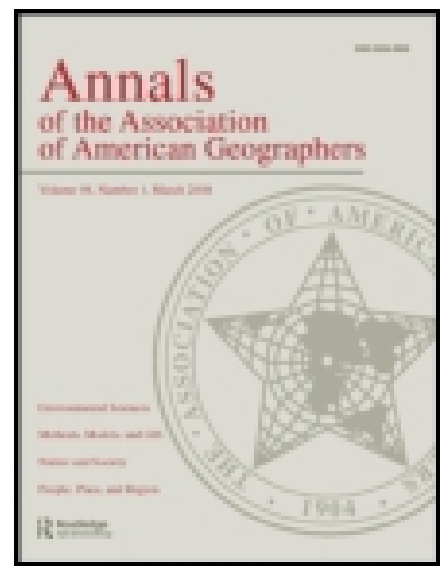

Annals of the Association of American Geographers

Publication details, including instructions for authors and subscription information:

http:// www.tandfonline.com/loi/ raag20

\title{
Space-Time Integration in a Dynamic Urbanizing World: Current Status and Future Prospects in Geography and GIScience
}

\author{
Martin Dijst ${ }^{a}$ \\ ${ }^{a}$ Department of Human Geography and Planning, Utrecht University \\ Published online: $06 \mathrm{~J}$ un 2013.
}

To cite this article: Martin Dijst (2013) Space-Time Integration in a Dynamic Urbanizing World: Current Status and Future Prospects in Geography and GIScience, Annals of the Association of American Geographers, 103:5, 1058-1061, DOI:

10.1080/00045608.2013.792171

To link to this article: http:// dx.doi.org/ 10.1080/00045608.2013.792171

\section{PLEASE SCROLL DOWN FOR ARTICLE}

Taylor \& Francis makes every effort to ensure the accuracy of all the information (the "Content") contained in the publications on our platform. However, Taylor \& Francis, our agents, and our licensors make no representations or warranties whatsoever as to the accuracy, completeness, or suitability for any purpose of the Content. Any opinions and views expressed in this publication are the opinions and views of the authors, and are not the views of or endorsed by Taylor \& Francis. The accuracy of the Content should not be relied upon and should be independently verified with primary sources of information. Taylor and Francis shall not be liable for any losses, actions, claims, proceedings, demands, costs, expenses, damages, and other liabilities whatsoever or howsoever caused arising directly or indirectly in connection with, in relation to or arising out of the use of the Content.

This article may be used for research, teaching, and private study purposes. Any substantial or systematic reproduction, redistribution, reselling, loan, sub-licensing, systematic supply, or distribution in any form to anyone is expressly forbidden. Terms \& Conditions of access and use can be found at http:// www.tandfonline.com/page/terms-and-conditions 


\title{
Space-Time Integration in a Dynamic Urbanizing World: Current Status and Future Prospects in Geography and GIScience
}

\author{
Martin Dijst \\ Department of Human Geography and Planning, Utrecht University
}

A t the 2011 Association of American Geographers (AAG) annual meeting in Seattle (April 12-16), a special symposium entitled "SpaceTime Integration in Geography and GIScience" was organized. This symposium focused on the research status, recent advances, and research needs of space-time integration, modeling, and analysis in geography and GIScience. About sixty sessions with more than 140 papers were organized on four concurrent tracks featuring geographers, GIScientists, modelers, computer programmers, Global Positioning System/geographic information system (GPS/GIS) scientists, climate change scientists, epidemiologists, ecologists, planners, transportation experts, and others with active research expertise in integrating space-time in GIS and geography. The event has been unprecedented in the history of the AAG, as Mike Goodchild remarked in the opening plenary session. The six invited speakers of the symposium's opening plenary session contribute to this Annals Forum. Each of the authors gives from a different perspective an excellent overview of the state-of-the-art knowledge in this field and outlines some avenues for future research. In this introduction to this Forum I set the stage on which the various contributions can play an important role.

Space and time belong to each other as two sides of the same coin. This was clearly discussed in the Middle Ages by Galileo: “A thing's place was no longer anything but a point in its movement, just as the stability of a thing was only its movement indefinitely slowed down" (Foucault 1986, 23). In reality, not only a thing is moving in time and space but, in general, all organic and nonorganic entities are (Hägerstrand 1970; Dijst 2009). In line with this perspective on space-time, Wegener (2004) has identified different types of urban processes that vary in their speed of change: the very slow processes of changing physical transport, communication and utility networks, and distribution of land uses; the long life cycle of housing, workplaces, and other nonresidential buildings; the relatively fast change in employment and household composition; and the very fast daily mobility flows of people and goods (Figure 1). Although not observed by Wegener, with the widespread use of fixed and mobile information and communication technologies nowadays (Schwanen, Dijst, and Kwan 2006; Kwan 2007; Urry 2007), the extremely fast flows of information, knowledge, and money in the realms of business and personal life can also be identified as relevant urban processes.

Besides these largely social and economic spatiotemporal processes, there are also natural spatiotemporal processes in the Earth system-the geosphere, the biosphere, the atmosphere, and the hydrosphere-that differ in their speed of change. Climate change, water, energy and nutrient flows, erosion, and other natural processes influence social and economic processes in urban systems. In reverse, in this Anthropocene geological epoch (Crutzen 2002), human-driven activities and associated footprints such as $\mathrm{CO}_{2}$ accumulation have become very pervasive and profound for the development of the Earth system (Steffen, Crutzen, and McNeill 2007; United Nations Environment Program 2012). Originally, the processes in the world were only of a natural kind, but with the rise of industrialization and urbanization, the natural system gradually became imbued with human-made technologies that mobilized people, goods, and information at an increasing pace (Steffen, Crutzen, and McNeill 2007). As a consequence, the world evolved into a very complex and highly dynamic web of encounters among flows within and between cities, which differ in nature and speed. As such, cities have become complex systems consisting of networks of broader or more local relations that are difficult to understand in a static manner (Castells 1996; Beaverstock et al. 2000; Graham and Marvin 2001; Limtanakool, Dijst, and Schwanen 2007).

This flow perspective on cities and urban systems in general shows that actually nothing is static, not even the built environment, and that flows do not stop at administrative borders. The organization and quality of places are the result of flows of, for example, information, capital, people, commodities, energy, water, waste, 
Figure 1. A flow perspective on urban systems. Drawn after Wegener (2004, 2005). (Color figure available online.)

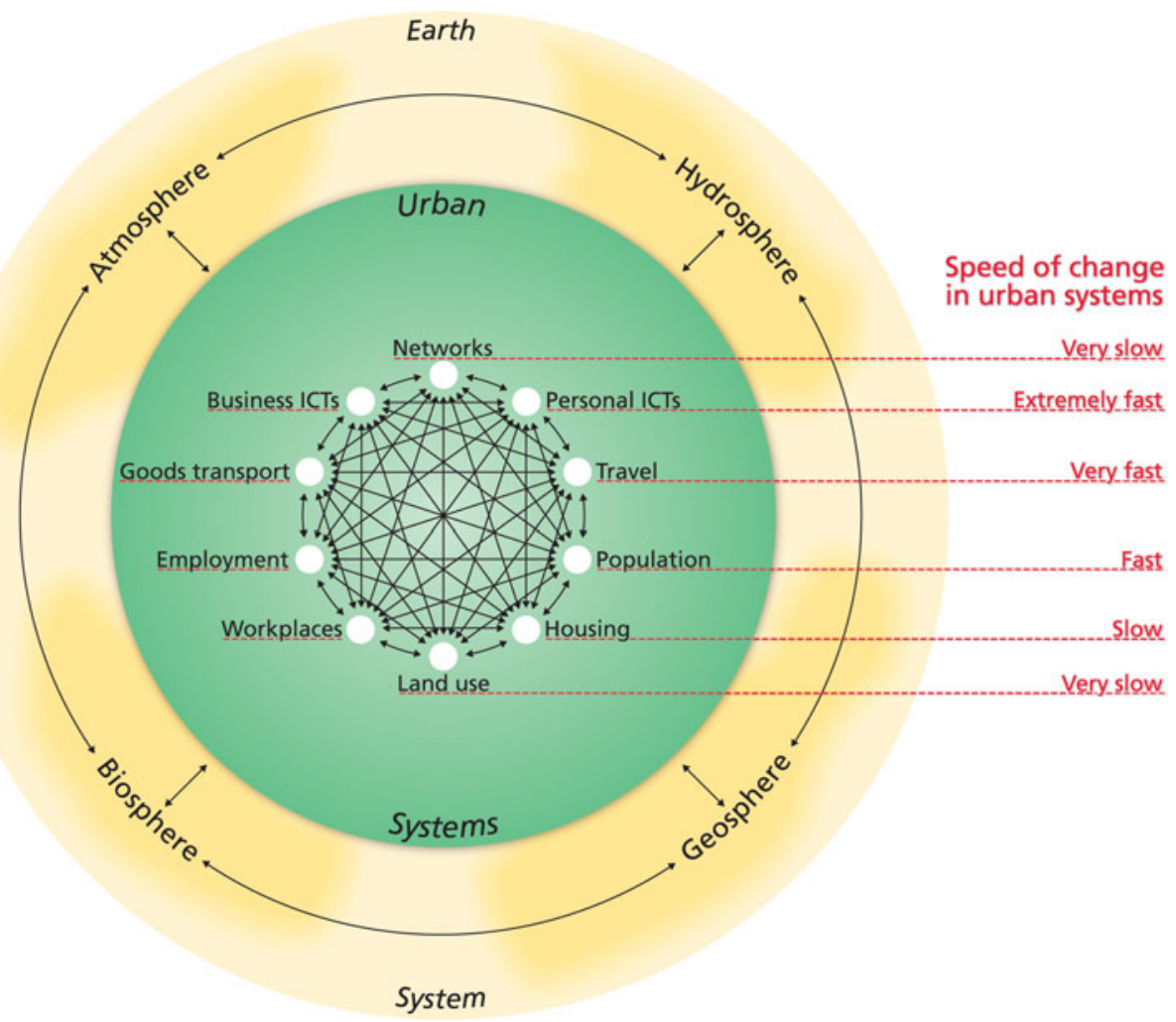

food, and air. On the other hand, the attractiveness, identity, and functionality of places have an impact on the strength and direction of these flows (Vromraad 2010). As such, flows and places are interconnected and interdependent (Cresswell 2004; Urry 2007). Foucault $(1986,23)$ expressed this as follows: "We live inside a set of relations that delineates sites which are irreducible to one another and absolutely not superimposable on one another." This flow perspective can be easily extended to the physical processes in outer space as well as the biological, psychological, and emotional processes taking place in human beings.

From the perspective of mobility, flows in urban systems are bundles of space-time paths drawn by people, other organisms, and nonliving elements like buildings, water, and air particles (Hägerstrand 1970; Dijst 2009). The timescale of these paths can vary from a split second to the whole life span of entities, which are constantly in movement even when immobile and only time goes by. Individuals are exposed to time-space trajectories of all of the moving elements or urban systems depicted in Figure 1 and that they encounter in various configurations and time spaces. This exposure to encounters with entities drawing their paths can be articulated by the term situation, which represents "'a position or condition at the moment' or 'a position with regard to surroundings"' (Hägerstrand 1982, 325). The environment or surrounding includes "both what is very close, even what is hidden under our roofs, and what is very distant, say, the clouds and the stars" (Hägerstrand 1982, 325-26). Actually, this means, as Latour $(1999,18)$ argued: "Contexts ... flow locally through networks." He asserted that all kinds of positions that people, other organisms, and things take in social, natural, and spatial systems come together in the form of a multitude of relations at the local level (see also Latour 2005).

From the perspective of an individual, time geography shows us that in two respects situations or contexts are dynamic. First, when a person is stationary in a certain physical context, other people and mobile objects and natural processes (e.g., sunrise, sunset, pollution, noise, and weather) can move in and out of her range of sensory perception. Second, while an individual is moving in space, physical contexts shift and alternate as the individual changes position over time (Dijst 2009; McQuoid and Dijst 2012). In these relational assemblages, which differ in duration, encounters between individuals and other entities present in the situations are possible through the sensory capacity of the body (sight, sound, touch, taste, and smell) and 
its physical engagement with its surroundings. Individuals experience these situations and emergent feelings about themselves and other individuals (Davidson and Milligan 2004; Hubbard 2005).

What can be the meaning of geography and geographic information systems in understanding this complex and dynamic system of flows? The articles in this Annals Forum discuss how different perspectives in geography and GIScience can help us analyze, model, visualize, and understand the spatiotemporal attributes of natural and social systems. The development and use of GIS originated in the 1960s and had largely focused on the advancement of cartographic tools for storing, manipulating, editing, and visualizing multiple thematic layers of locational data until the 1980s (Goodchild this issue; Richardson this issue). Geographic data about the various urban processes shown in Figure 1 were "laboriously gathered and integrated within the system well after it was collected" (Richardson this issue). As Richardson describes in his article, however, real-time space-time integration (RTI) became possible only when GPS technologies were integrated with interactive GPS/GIS software in the 1980s. Incorporation of miniaturized RTI GPS/GIS systems in mobile (navigation) devices in combination with electronic sensors, which measure, for example, pollution, noise, health condition, and so forth, functions as a double-edged sword. These devices can collect a rich variety of spatiotemporal environmental data while also giving users real-time feedback on the environments through which they navigate. Based on these ubiquitous developments in data availability and use, Richardson identifies a range of research challenges. In addition, to foster continued innovations he makes a strong plea to connect more firmly the technologies and applications in GIS with the key theories in geography.

Central to Goodchild's contribution is the statement that geography and GIScience can play an important exploratory role in a science of integration. This means contextualizing in space and time the knowledge of economics, sociology, ecology, and other social and environmental sciences. Interdisciplinary analysis of the interactions among these phenomena and processes serves to bridge different disciplines. To phrase it differently, disciplinary knowledge of the various natural and social processes as depicted in Figure 1 can be integrated by studying them in specific time spaces. GIScience offers the analytical and visualization methods for this integrating process. It also provides good opportunities to discuss the results in multidisciplinary decision-support settings to translate the integrated knowledge on social and natural phenomena and processes into useful and shared advice to decision makers (see also Geertman 2006). The large variety of space-time data and questions keeps the emergence of a single space-time GIS waiting, however. Instead, various forms of space-time GIS will evolve, and Goodchild's article discusses seven of them.

Kwan (this issue) argues that geography and other social sciences have largely applied spatial concepts as static notions. Alternatively, and in line with the flow perspective presented earlier, she shows the relevance of temporally integrated human geographies for gaining new insights into studies of racial and ethnic segregation, environmental exposure, and accessibility. Her theoretical framework is informed by the new mobilities paradigm (Urry 2007) and geographies of encounter (Valentine 2008). It is a situational approach that emphasizes the meaning of exposure to contacts with particular environmental entities as individual space-time paths unfold. Her article highlights the possibility that research results can be erroneous without taking into account the role of time and human mobility when examining these three phenomena. It also discusses some prospective conceptual and methodological attempts to reach temporally integrated geographies.

Historical GIS is the subject of Bol's (this issue) article. Although traditionally geography recognizes that the change of spatial features over time and history shows awareness of the change over time in many places across space, Bol argues that both disciplines remain separate even after the "spatial turn" in history (Guldi 2013). According to him, historical GIS will not bring the integration. It might be, however, that a reconceptualization of fundamental notions in geography and GIScience from a flow perspective might be a good start for a reconciliation between geography and history. In his article, Bol focuses further on the meaning of names as an interface between the history and the geography of places. He makes a plea and sets a research agenda for the development of a world historical gazetteer.

Written by authors from Asia, the last two articles of this Annals Forum focus on the development of space-time integration in geography and GIScience in China and Japan. Chai (this issue) presents an interesting overview of the introduction, development, and prospects of space-time behavior research in China. In 1996, he first introduced time geography to China through a Chinese research project. Thereafter, time-geographic studies were carried out to examine various urban issues in many coastal and inland cities. Inspired by the work of geographers in Western 
countries, important methodological progress has also been made in China. Chai concludes that the major challenge for Chinese scholars is to develop theories from a space-time behavior perspective that are able to understand Chinese transformation processes. Nakaya (this issue), from Japan, discusses the relevance of 3D space-time cubes for analyzing and visualizing space-time relationships for three issues outside the realm of time geography. His Japanese case studies are the distribution of crime events over space-time locations, the impact of natural disasters on the demolition of cultural heritage in the last thirteen centuries, and integration of historical narratives with spatiotemporal data.

In each of these articles, many intriguing issues are discussed. In light of these discussions and the flow perspective presented in this editorial, one major challenge for future space-time integration remains. In line with the pragmatist view of life, the world can be seen as existing in a constant state of flux. Such a dynamic perspective on life recognizes that different processes with different speeds in urban systems interact in specific spatiotemporal assemblages, which result in changes in the course of these processes. Such a "flow turn" in geography and GIScience, of which the mobility turn (Sheller and Urry 2006) could be seen as a branch, could bring us closer to Goodchild's science of integration.

\section{References}

Beaverstock, J. V., R. G. Smith, P. J. Taylor, D. R. F. Walker, and H. Lorimer. 2000. Globalization and world cities: Some measurement methodologies. Applied Geography 20:43-63.

Castells, M. 1996. The rise of the network society. Oxford, UK: Blackwell.

Cresswell, T. 2004. Place: A short introduction. Malden, MA: Blackwell.

Crutzen, P. J. 2002. Geology of mankind. Nature 415:23.

Davidson, J., and C. Milligan. 2004. Embodying emotion sensing space: Introducing emotional geographies. Social B3 Cultural Geography 5:523-32.

Dijst, M. 2009. Time geographical analysis. In International encyclopedia of human geography, ed. R. Kitchin and N. Thrift, 266-78. Oxford: Elsevier.

Foucault, M. 1986. Of other spaces. Diacritics 16:22-27.

Geertman, S. 2006. Potentials for planning support: A planning-conceptual approach. Environment and Planning B 33:863-80.

Graham, S., and S. Marvin 2001. Splintering urbanism: Networked infrastructures, technological mobilities, and the urban conditions. London and New York: Routledge.

Guldi, J. 2013. The spatial turn in history. Charlottesville, VA: Institute for Enabling Geospatial Scholarship, Scholars' Lab, University of Virginia Library. http://spatial.scholarslab.org/spatial-turn/disciplinary perspectives/the-spatial-turn-in-history/ (last accessed 26 April 2013).

Hägerstrand, T. 1970. What about people in regional science? Papers of the Regional Science Association 24:7-21.

- 1982. Diorama, path and project. Tijdschrift voor Economische en Sociale Geografie 73:323-39.

Hubbard, P. 2005. The geographies of "going out": Emotion and embodiment in the evening economy. In Emotional geographies, ed. J. Davidson, L. Bondi, and M. Smith, 117-34. Hamphshire, UK: Ashgate.

Kwan, M.-P. 2007. Mobile communications, social networks, and urban travel: Hypertext as a new metaphor for conceptualizing spatial interaction. The Professional Geographer 59:434-46.

Latour, B. 1999. On recalling ANT. In Actor network theory and after, ed. J. Law and J. Hassard, 15-25. Oxford, UK: Blackwell.

- 2005. Reassembling the social: An introduction to actornetwork-theory. Oxford, UK: Oxford University Press.

Limtanakool, N., M. J. Dijst, and T. Schwanen. 2007. Polycentric urban systems in North West Europe: A theoretical methodological and empirical exploration of urban flows. Urban Studies 44:2123-45.

McQuoid, J., and M. Dijst. 2012. Bringing emotions to time geography: The case of mobilities of poverty. Journal of Transport Geography 23:26-34.

Schwanen, T., M. Dijst, and M.-P. Kwan. 2006. The Internet, changing mobilities and urban dynamics. Urban Geography 27:585-89.

Sheller, M., and J. Urry. 2006. The new mobilities paradigm. Environment and Planning A 38:207-26.

Steffen, W., P. J. Crutzen, and J. R. McNeill. 2007. The anthropocene: Are humans now overwhelming the great forces of nature? AMBIO: A Journal of the Human Environment 26:614-21.

United Nations Environment Programme. 2012. Fifth global environment outlook: Environment for the future we want. Geneva, Switzerland: UNEP.

Urry, J. 2007. Mobilities. Cambridge, UK: Polity.

Valentine, G. 2008. Living with difference: Reflections on geographies of encounter. Progress in Human Geography 32:321-35.

Vromraad. 2010. VROM council recommendations for sustainable urban development. The Hague, The Netherlands: Vromraad.

Wegener, M. 2004. Overview of land-use transport models. In Transport geography and spatial systems, ed. D. A. Hensher and K. J. Button, 127-46. Kidlington, UK: Pergamon/Elsevier Science.

- 2005. Integrated land use and mobility planning. Paper presented at the Towards Sustainable Mobility II conference, Cologne, Germany.

Correspondence: Faculty of Geosciences, Utrecht University, P.O. Box 80115, 3508 TC Utrecht, The Netherlands, e-mail: m.j.dijst@uu.nl. 